\title{
Linear Alkanes and Reproductive Status of Polistes versicolor (Hymenoptera: Vespidae) Females in Winter Aggregates
}

\author{
JHS BRITO ${ }^{1,2}$, WF ANTONIALli-JUnioR ${ }^{1}$, TS MONTAGNA ${ }^{1}$, A MENDONÇA ${ }^{1,3}$, D SGUARIZI-ANTONIO ${ }^{1,2}$, YR SÚAREZ $^{1}$, CAL CARdoso $^{1}$ \\ 1 - Laboratório de Ecologia Comportamental (LABECO), Centro de Estudos em Recursos Naturais (CERNA), Universidade Estadual de Mato \\ Grosso do Sul, Dourados-MS, Brazil \\ 2 - Programa de Pós Graduação em Recursos Naturais, Universidade Estadual de Mato Grosso do Sul, Dourados-MS, Brazil \\ 3 - Programa de Pós Graduação em Entomologia e Conservação da Biodiversidade, Universidade Federal da Grande Dourados, Mato Grosso \\ do Sul, Brazil
}

\section{Article History}

\section{Edited by}

Sergio Ricardo Andena, UEFS, Brazil

Received 06 April 2016

Initial acceptance 12 September 2016

Final acceptance 12 September 2017

Publication date 17 October 2017

\section{Keywords}

Social insects, cuticular compounds, wasp, chemical signature, chromatography.

\section{Corresponding author}

Denise Sguarizi Antonio

Universidade Estadual do Mato Grosso

do Sul, Cidade Universitária

Rodovia Dourados/Itahum, km 12,

CEP 79804-970, Dourados-MS, Brasil.

E-Mail: denisesguarizi@hotmail.com

\begin{abstract}
Female wasps such as Polistes versicolor can form aggregates to face weather conditions that are not suitable to sustain their colonies. The interactions between individuals in these aggregates, just as in other associations, are probably facilitated by chemical signals. Of these compounds some of the most efficient during social interactions of insects are those called contact pheromones or superficial pheromones. This special type of pheromones, known as cuticular hydrocarbons, can be found in insects cuticle. They facilitate the differentiation of caste, species and nestmates, and may be important indicators of dominance as well as fertility. Some studies indicate that linear alkanes are important cuticular compounds for intraspecific recognition and discrimination. The aim of this study was to evaluate the relationship between reproductive physiologic condition and the linear alkanes present in the cuticle of females of $P$. versicolor in aggregates employing Gas Chromatography with Flame Ionization Detector (GC-FID). Females from distinct aggregates were differentiated by the chemical composition of their cuticle. In each aggregate, there was difference in cuticular chemical composition between females with different ovarian development degrees, allowing the distinction between inseminated and non-inseminated females.
\end{abstract}

\section{Introduction}

In social wasps, winter aggregates are composed of hibernating females, originated from colonies abandoned at the beginning of the cold season (Ihering, 1904). They usually occur when atmospheric conditions are not adequate to support their colonies (Tannure \& Nascimento, 1999; González et al., 2002; Gobbi et al., 2006). Females remain in this state for a variable period between one to four months, and later they disperse and found new colonies (González et al., 2002; Gobbi et al., 2006, 2009).

The types of interactions involved in winter aggregates of social wasps were well investigated in species of temperate climate (Strassmann, 1991; Dapporto et al., 2004; Dapporto \& Palagi, 2006). In Polistes dominula Christ 1791, social interactions were observed with wasps performing external tasks, feeding the others by trophallaxis (Dapporto et al., 2005). However, few studies have explored these aspects in wasps that inhabit tropical regions.

In a study by Gobbi et al. (2006) with P. versicolor aggregates, potential queens (females inseminated and with well-developed ovary) had a significantly larger size, a fact that was associated by the authors with greater accumulation of adipose tissue (Gobbi \& Zucchi, 1985), so that the wasps can go through an unfavorable period. In fact, the particular conditions of these females aggregates even in tropical regions is an adaptation that allows females to survive until more favorable environmental conditions for founding new colonies (Gobbi et al., 2006).

Although few interactions occur in these aggregates, it is important for the females that these associations are 
maintained. The coherence of these aggregates might be facilitated by chemical compounds, which are the main signals exchanged during social interactions in colonies of social wasps (Wilson, 1971). Indeed, social insects present a complex organization system that is mediated by several chemical compounds called pheromones (Billen, 2006). Among these pheromones, there is a particular group called contact pheromones that are found in the insects' cuticle (Lockey, 1988). These compounds are the so-called cuticular hydrocarbons (CHCs). Their primary function is to prevent water loss, acting as a protective coating for insects (Blomquist \& Bagnères, 2010). Additionally, CHCs act as contact or surface pheromones (Abdalla et al., 2003; Ginzel, 2010; Neves et al., 2012; Olaniran et al., 2013) that are involved in the identification of co-specifics. Furthermore they facilitate the distinction of individuals according to their function in the colony, physiological status and hierarchical rank (Provost et al., 2008), thus acting as a chemical signature of the colony (Neves et al., 2012).

Among the cuticular compounds there are basically 3 categories, linear alkanes, branched alkanes and alkenes (Devigne \& Biseau, 2012; Olaniran et al., 2013). While several studies have indicated branched alkanes as the most important compounds for intraspecific recognition (BonavitaCougourdan et al., 1991; Dani et al., 1996; Lorenzi et al., 1997; Blomquist \& Bagnères, 2010; Richard \& Hunt, 2013), others demonstrated the role of linear alkanes for the same purpose (Lorenzi et al., 2004: P. dominula; Tannure-Nascimento et al., 2007: P. satan Bequaert 1940). In addition to nestmate identity, the CHCs may signal the fertility and physiological condition of females (Van Oystaeyen et al., 2014; Oi et al., 2015a; Oi et al., 2015b). Here, in particular, linear alkanes of queens have been proposed to signal their condition within the colony and further induce the workers to remain sterile (Van Oystaeyen et al., 2014).

Therefore, despite the knowledge of the strong correlation between physiological condition and cuticular composition of females in colonies of social Hymenoptera, few studies have explored this subject in depth in social wasps, especially using linear alkanes as signs to distinguish members of the same species. In this sense, the aim of this study was to evaluate the relationship between reproductive physiology and the cuticular composition of linear alkanes in females of $P$. versicolor Olivier 1791 in winter aggregates.

\section{Materials and Methods}

\section{Wasp samples}

Sixty nine females of the wasp $P$. versicolor were evaluated in two winter aggregates, both sampled in Dourados, Mato Grosso do Sul, Brazil (22 ' 12 '43' S, $54^{\circ} 54$ ' 53', W) in May/2013.

The aggregates were approximately $30 \mathrm{~km}$ apart, with Aggregate 1 (A1) located on a bridge and Aggregate 2 (A2) on a roof. All individuals from the aggregates were collected at dusk, wrapping them with a sterile plastic container. In the laboratory, all subjects were anesthetized in freezer $\left(4^{\circ} \mathrm{C}\right)$ for $30 \mathrm{~min}$. Subsequently, with the aid of gloves and tweezers, the mesosome and metasome were removed and stored separately in sterile eppendorf vials.

For the analysis of physiological conditions of females, the metasomes were fixed in absolute ethanol (VETEC, $99.8 \%$ ), kept in eppendorf vials and stored for 6 months at $4^{\circ} \mathrm{C}$ for further analysis of ovarian development and insemination.

The cuticular hydrocarbons were extracted from the mesosome immediately after the collection (see below for details) and analyzed by Gas Chromatography - Flame Ionization Detector (GC-FID).

\section{Analysis of reproductive physiology}

For the analysis of ovarian development, the metasomes of females were dissected, and the ovarian development stages were analyzed using a stereomicroscope Zeiss Stemi 2000-C, equipped with an ocular micrometer and digital camera.

The ovarian development stage classification was performed according to the developmental degree of ovarioles (adapted from Baio et al., 2004). Ovary type 1: presence of filamentous ovarioles (First stage); ovary type 2: ovarioles slightly swollen and some mature oocytes (Second stage) (Gobbi et al., 2006; Oliveira et al., 2007); ovary type 3: large ovarioles with well developed oocytes (Third stage) (Gobbi et al., 2006).

To assess whether females were inseminated, basic fuchsin colorimetric reagent was applied to the spermatheca, which acquires opaque or pearly staining in the presence of sperm (Noda et al., 2003).

\section{Cuticular hydrocarbons: extraction and GC-FID analysis}

The mesosomes were submitted to the extraction process for subsequent analysis by GC-FID. The cuticular constituents of each sample were extracted with $1 \mathrm{~mL}$ hexane (HPLC grade, Tedia) for 2 minutes. After filtration, the solvent was removed in a laminar flow exhaustion chapel. Each extract was dissolved in $50 \mu \mathrm{L}$ of hexane for GC-FID analysis.

The samples and a standard mixture of linear alkanes $\left(\mathrm{C}_{7}-\mathrm{C}_{31}\right.$, Sigma Aldrich with purity $\left.\geq 90 \%\right)$ were analyzed using a gas chromatograph with flame ionization detector (Thermo Scientific - Focus GC, San Jose, CA, USA) equipped with an OV-5 capillary column ( $5 \%$ phenyl dimethylpolysiloxane, 30 $\mathrm{m}$ long x $0.25 \mathrm{~mm}$ ID x $0.25 \mu \mathrm{m}$ film thickness, Ohio Valley Specialty Company, Marietta, OH, USA). The injector and detector were kept at $280^{\circ} \mathrm{C}$ using $\mathrm{N}_{2}$ as the carrier gas with a flow rate of $1.0 \mathrm{~mL} / \mathrm{min}$ ). The oven temperature was kept at $50{ }^{\circ} \mathrm{C}$ for three minutes, reaching $280^{\circ} \mathrm{C}$ at a rate of $8^{\circ} \mathrm{C} /$ min, and remaining at $280{ }^{\circ} \mathrm{C}$ for 15 minutes. The injection was in splitless mode, and $1.0 \mu \mathrm{l}$ of sample was injected. The chromatograms were recorded using the software Chrom Quest 5.0, and analyzed with the software Workstation Chrom Data Review. The linear alkanes analyzed by GC-FID were identified by comparison with the retention times of the standards $\mathrm{C}_{7}-\mathrm{C}_{31}$ alkenes. 
We used the values of the relative percentual area of the linear alkanes, obtained by GC-FID. To assess whether there are significant differences among females from different aggregates and physiological status a canonical discriminant analysis was performed.

\section{Results}

Three degrees of ovarian development were identified in females of $P$. versicolor from the two aggregates analyzed (Fig 1, Table 1). In Aggregate 1 (A1) 15\% of the females were inseminated, $33.3 \%$ of which showed ovary type 1 (Fig 1A), $50 \%$ ovary type 2 (Fig 1B) and $16.7 \%$ ovary type 3 (Fig 1C). While in Aggregate 2 (A2), $17.2 \%$ of the females were inseminated, $80 \%$ of which presented ovary type 1 and $20 \%$ ovary type 2 (Figs $1 \mathrm{~A}$ and $1 \mathrm{~B}$ ).

25 linear alkanes were identified ranging from $\mathrm{C}_{7}$ to $\mathrm{C}_{31}$. There was significant difference in linear alkanes composition between females of Aggregate 1 (Wilks' Lambda $=0.07, \mathrm{~F}=$ 49.02; $p>0.05$ ), based on their ovarian development degrees. The first canonical root explained $72 \%$ of these results (Fig 2A).

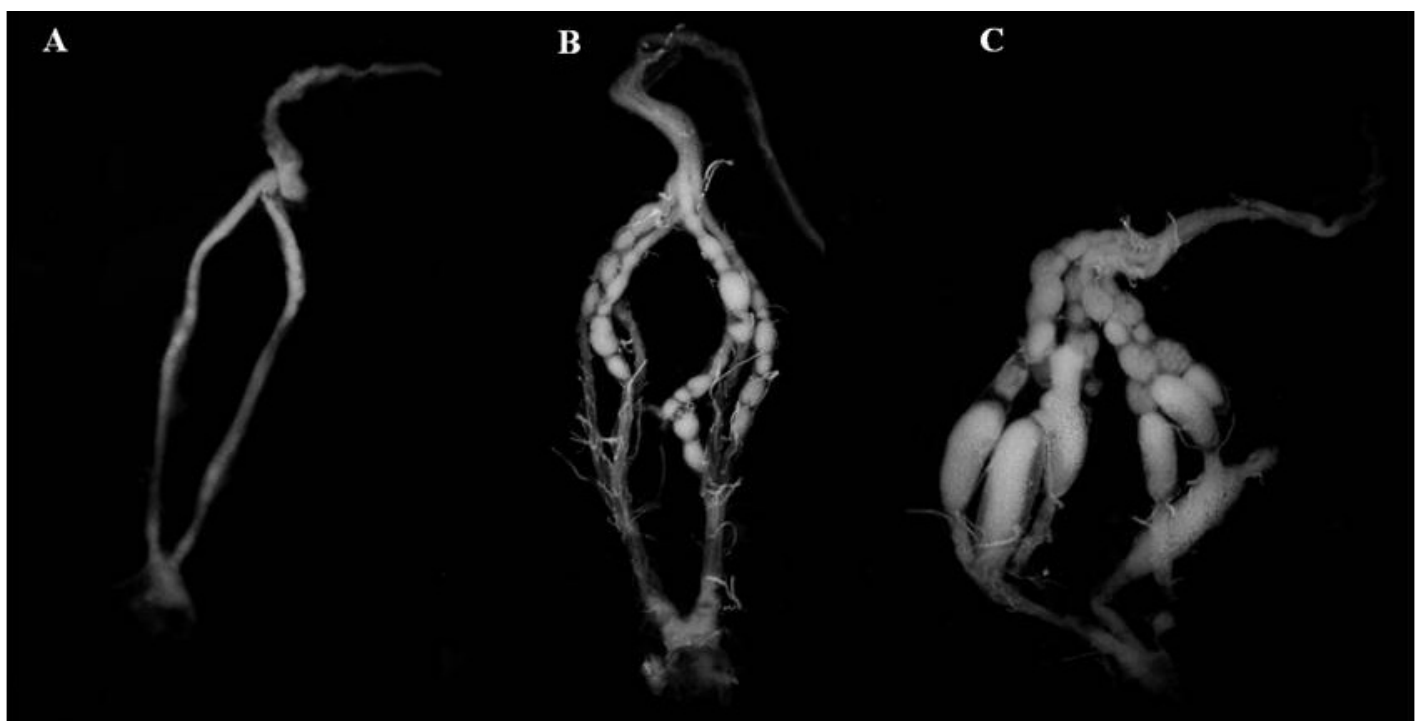

Fig 1. Different ovarian development degrees found in two wasps of Polistes versicolor. A) first stage of ovarian development, ovary type 1; B) second stage of ovarian development, ovary type 2; C) third stage of ovarian development, ovary type 3.

Table 1. Percentage of Polistes versicolor of each different ovarian development stage and spermatheca insemination in two winter aggregates.

\begin{tabular}{ccccccc}
\hline Aggregate & \multicolumn{2}{c}{ Stage of ovarian development (SOD) } & \multicolumn{2}{c}{ Spermatheca } & Total of females \\
\hline & First & Second & Third & Inseminated & Non-inseminated \\
A1 & 52.5 & 40.0 & 7.5 & 15.0 & 85.0 & 40 \\
A2 & 48.3 & 51.7 & - & 17.2 & 82.8 & 29 \\
\hline
\end{tabular}
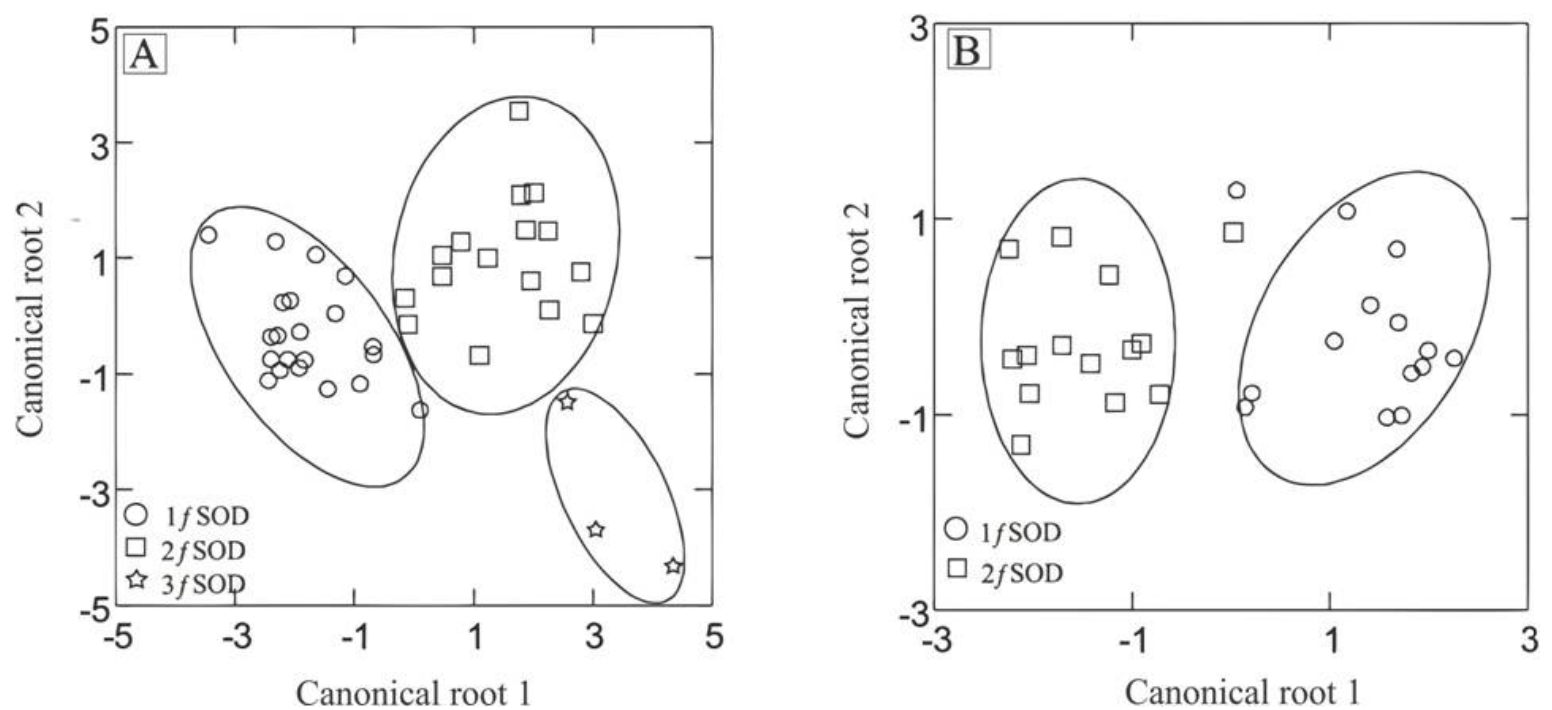

Fig 2. Discriminant analysis of linear alkanes present in Polistes versicolor females from two aggregates and with different ovarian development degrees obtained by GC-FID. A) Aggregate 1, B) Aggregate 2, $1^{\circ} \mathrm{SOD}=$ first stage of ovarian development, $2^{\circ} \mathrm{SOD}=\mathrm{second}$ stage of ovarian development, $3^{\circ} \mathrm{SOD}=$ third stage of ovarian development. 
Significant differences were also found between females of Aggregate 2 (Wilks' Lambda $=0.32, F=9.31 ; p>0.05$ ), with the first canonical root explaining $84 \%$ of results (Fig $2 \mathrm{~B}$ ).

The same type of analysis showed significant differences in cuticular linear alkanes composition between inseminated and non-inseminated females (Wilks' Lambda $=0.09, \mathrm{~F}=$ 47.02; $\mathrm{p}<0.05$ ), and the first canonical root explains $76 \%$ of results (Fig 3).

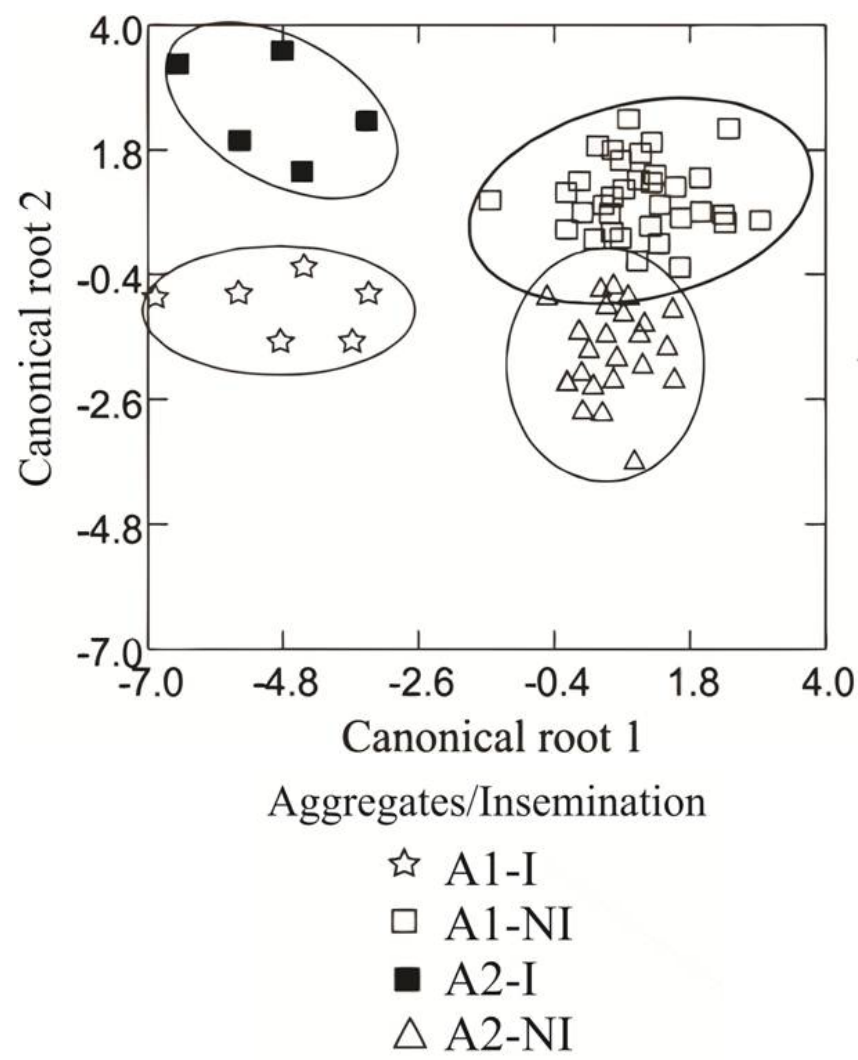

Fig 3. Discriminant analysis of linear alkanes present in inseminated and non-inseminated females from two aggregates of Polistes versicolor obtained by GC-FID. A1= Aggregate 1, A2= Aggregate $2, \mathrm{I}=$ inseminated females and $\mathrm{NI}=$ non-inseminated females.

\section{Discussion}

Females of $P$. versicolor from Aggregate 1 presented 3 degrees of ovarian development and females from Aggregate 2 presented 2 degrees of ovarian development, the proportion of linear alkanes differed significantly between females with different ovarian development degrees and also between inseminated and non-inseminated females.

Females with different ovarian development degrees had significantly different linear alkane composition (Fig 2A and $\mathrm{B}$ ), which indicates that these category of compounds may be important to signal the reproductive status of these females. This is in agreement with other studies on Hymenoptera females that reported a variation in cuticular chemical composition due to the fertility (Cuvillier-Hot et al., 2001; Sledge et al., 2001; Biseau et al., 2004; Will et al., 2012; Van Oystaeyen et al., 2014). Hence, there is apparently a strong correlation between reproductive status and cuticular chemical composition in females of social insects colonies (Sledge et al., 2001; Monnin, 2006).

Dapporto et al. (2004) studying colonies of $P$. dominula found qualitative differences in cuticular chemical composition between wasps with different reproductive status. The same species was investigated by Sledge et al. $(2001,2004)$ who found similar results. Likewise, Bonckaert et al. (2012), investigating colonies of Vespula vulgaris (Linnaeus), also found significant differences between cuticular composition among females with different physiological conditions. Studies with other social Hymenoptera, as in colonies of the ant Temnothorax unifasciatus (Latreille) (Brunner et al., 2009), also found significant differences between the cuticular chemical composition of females of differing reproductive status. Likewise, Nunes et al. (2009) found similar results in the bee Schwarziana quadripunctata (Lepeletier). However, it should be noted that these studies evaluated all cuticular compounds.

Despite studies have shown that, indeed, cuticular chemical compounds, especially branched alkanes and alkenes, may signal the physiological status of females, TannureNascimento (2007) assessed that in colonies of Polistes satan linear alkanes can also play this role. Therefore, despite these compounds being more involved with the ability of the cuticle to prevent desiccation (Blomquist, \& Bagnères, 2010), our results demonstrate that the functions of these compounds, as well as of others might have been underestimated.

According to our results, insemination also leads to significant differences between linear alkanes composition of females (Fig 3). Torres et al. (2014) studying the relationship between cuticular chemical profile and physiological condition of $P$. versicolor females, found correlation between ovarian development and spermatheca condition. Soares et al. (2014) also found similar results studying colonies of Polistes ferreri Saussure 1853.

Studies with other social Hymenoptera, such as ants of the species Cardiocondyla obscurior Wheeler 1929, in which inseminated and non-inseminated females showed quantitative differences between some linear alkanes, provide evidence of these compounds importance for signaling reproductive status (Will et al., 2012). Biseau et al. (2004) found qualitative differences in linear and branched alkanes between inseminated and non-inseminated females of the ant Linepithema humile Mayr 1868. Other studies such as those by Oettler et al. (2008) with Crematogaster smithi Creighton 1950 and Oppelt and Heinze (2009) with Leptothorax gredleri Mayr 1855 also reported that linear alkanes may be important for signaling the reproductive status of females in their colonies.

In aggregates, in particular, these signals can be used during interactions between females or serve to identify which females are already inseminated allowing males to identify them and, thus, invest their efforts in females that have not been inseminated, when they may still be associated with males. Indeed, according to Blomquist and Bagnères (2010) 
social pheromones of queens have probably evolved from preexisting fertility signals targeted at males, for example, in the context of choice or partner attraction. Thus, linear alkanes seem to be as important as other compounds involved in intraspecific signaling.

Therefore, females of $P$. versicolor in aggregates may have three different degrees of ovarian development. All these females can be identified by the proportion of linear alkanes in their cuticle, corroborating the results of other studies that investigated the importance of this category of compounds for signaling reproductive status and, therefore, also be responsible for mediating social interactions in wasps.

\section{Acknowledgments}

Agência Brasileira de Inovação (FINEP), Coordenação de Aperfeiçoamento de Pessoal de Nível Superior (CAPES), Fundação de Apoio ao Desenvolvimento do Ensino, Ciência e Tecnologia do Estado de Mato Grosso do Sul (Fundect) and Conselho Nacional de Desenvolvimento Científico e Tecnológico (CNPq), and productivity grants of WFAJ and CALC.

\section{References}

Abdalla, F.C., Jones, G.R., Morgan, E.D. \& Cruz-Landim, C. (2003). Comparative study of the cuticular hydrocarbon composition of Melipona bicolor Lepeletier, 1836(Hymenoptera, Meliponini) workers and queens. Genetics and Molecular Research, 2: 191-199.

Baio, M.V., Noll, F.B. \& Zucchi, R. (2004). Morphological caste differences, variation according to colony cycle, and non-sterility of workers in Brachygastra augusti (Hymenoptera, Vespidae, Epiponini), a Neotropical swarmfounding wasp. Journal of the New York Entomological Society, 111: 243-253.

Billen, J. (2006). Signal variety and communication in social insects. Proceedings of the Section Experimental and Applied Entomology-Netherlands Entomological Society, 17: 9-25.

Biseau, J.C., Passera, L., Daloze, D. \& Aron, S. (2004). Ovarian activity correlates with extreme changes in cuticular hydrocarbon profile in the highly polygynous ant, Linepithema humile. Journal of Insect Physiology, 50: 585-593.

Blomquist, G. \& Bagnères, A.G. (2010). Insect hydrocarbons: biology, biochemistry and chemical ecology. Cambridge: Cambridge University Press.

Bonavita-Cougourdan, A., Theraulaz, G., Bagnéres, A.G., Roux, M., Pratte, M., Provost, E. \& Clément J.L. (1991). Cuticular hydrocarbons, social organization and ovarian development in a polistine wasp: Polistes dominulus Christ. Comparative Biochemistry and Physiology Part B: Comparative Biochemistry, 100: 667-680.

Bonckaert, W., Drijfhout, F.P., D’Ettorre, P., Billen, J.
\& Wenseleers, T. (2012). Hydrocarbon signatures of egg maternity, caste membership and reproductive status in the common wasp. Journal of Chemical Ecology, 38: 42-51. doi: 10.1007/s10886-011-0055-9

Brunner, E., Kroiss, H. \& Heinze, J. (2009). Chemical correlates of reproduction and worker policing in a myrmicine ant. Journal of Insect Physiology, 55: 19-26.

Cuvillier-Hot, V., Cobb, M., Malosse, C. \& Peeters, C. (2001). Sex, age and ovarian activity affect cuticular hydrocarbons in Diacamma ceylonense, a queenless ant. Journal of Insect Physiology, 47: 485-493.

Dani, F.R., Morgan, E.D. \& Turillazzi, S. (1996). Dufour gland secretion of Polistes wasp: chemical composition and possible involvement in nestmate recognition (Hymenoptera: Vespidae). Journal of Insect Physiology, 42: 541-548.

Dapporto, L., Theodora, P., Spacchini, C., Pieraccini, G. \& Turillazzi, S. (2004). Rank and epicuticular hydrocarbons in different populations of the paper wasp Polistes dominulus (Christ) (Hymenoptera,Vespidae). Insectes Sociaux, 51: 279-286.

Dapporto, L., Sledge, F. M., \& Turillazzi, S. (2005). Dynamics of cuticular chemical profiles of Polistes dominulus workers in orphaned nests (Hymenoptera, Vespidae). Journal of Insect Physiology, 51: 969-973.

Dapporto, L. \& Palagi, E. (2006) Wasps in the shadow: looking at the pre-hibernating clusters of Polistes dominulus. Annales Zoologici Fennici, 43: 583-594.

Devigne, C. \& Biseau, J.C. (2012). The differential response of workers and queens of the ant Lasius niger to an environment marked by workers: Ants dislike the unknown. Behavioural Processes, 91: 275-281. doi.org/10.1016/j. beproc.2012.09.008.

Ginzel, M.D. (2010). Hydrocarbons as contact pheromones of longhorned beetles (Coleoptera: Cerambycidae). Insect Hydrocarbons: Biology, Biochemistry and Chemical Ecology. Cambridge University Press, New York, 375-389.

Gobbi, N., \& Zucchi, R. (1985). On the ecology of Polistes versicolor versicolor (Oliver) in Southern Brazil (Hymenoptera, vespidae, polistini). II: Colonial productivity. Naturalia, 10, 21-25.

Gobbi, N., Noll, F.B. \& Penna, M.A.H. (2006). "Winter" aggregations, colony cycle, and seasonal phenotypic change in the paper wasp Polistes versicolor in subtropical Brazil. Naturwissenschaften, 93: 487-494.

Gobbi, N., Govone, J.S., Pinto, N.P.O. \& Prezoto, F. (2009). Produtividade em colônias de Polistes (Aphanilopterus) versicolor Olivier, 1791 (Hymenoptera: Vespidae, Polistinae). Revista Brasileira de Zoologia, 11: 191-199.

González, J.A., Nascimento, F.S. \& Gayubo, S.F. (2002). Observations on the winter aggregations of two polistine 
paper wasps (Hymenoptera Vespidae Polistinae). Tropical Zoology, 15: 1-4.

Ihering, R.V. (1904). As vespas sociais do Brasil. Revista do Museu Paulista, 6: 97-309.

Lockey, K.H. (1988). Lipids of the insect cuticle: origin, composition and function. Comparative Biochemistry and Physiology Part B, 89: 595-645.

Lorenzi, M.C., Bagnères, A.G., Clément, J.L. \& Turillazzi, S. (1997). Polistes biglumis bimaculatus epicuticular hydrocarbons and nestmate recognition (Hymenoptera, Vespidae). Insectes Sociaux, 44: 123-138.

Lorenzi, M.C., Sledge, M.F., Laiolo, P., Sturlini, E. \& Turillazzi, S. (2004). Cuticular hydrocarbon dynamics in young adult Polistes dominulus (Hymenoptera: Vespidae) and the role of linear hydrocarbons in nestmate recognition systems. Journal of Insect Physiology, 50: 935-941.

Monnin, T. (2006). Chemical recognition of reproductive status in social insects. Annales Zooogici Fennici, 43: 515530 .

Neves, E.F., Andrade, L.H.C., Súarez, Y.R., Lima, S.M., Antonialli-Junior. W.F. (2012). Age-related changes in the surface pheromones of the wasp Mischocyttarus consimilis (Hymenoptera: Vespidae). Genetics and Molecular Research, 11: 1891-1898. doi.org/10.4238/2012.July.19.8

Noda, S.C.M., Shima, S.N. \& Noll, F.B. (2003). Morphological and physiolocal caste differences in Synoeca cyanea (Hymenoptera, Vespidae, Epiponini) according to the ontogenetic development of the colonies. Sociobiology, 41: 547-570.

Nunes, T.M., Turatti, I.C.C., Mateus, S., Nascimento, F.S., Lopes, N.P. \& Zucchi, R. (2009). Cuticular hydrocarbons in the stingless bee Schwarziana quadripunctata (Hymenoptera, Apidae, Meliponini): differences between colonies, castes and age. Genetics and Molecular Research, 8: 589-595.

Oettler, J., Schmitt, T., Herzner, G. \& Heinze, J. (2008). Chemical profiles of mated and virgin queens, egg-laying intermorphs and workers of the ant Crematogaster smithi. Journal of Insect Physiology, 54: 672-679.

Oi, C.A., Van Oystaeyen, A., Oliveira, R.C., Millar, J.G., Verstrepen, K.J., Van Zweden, J.S., \& Wenseleers, T. (2015a). Dual effect of wasp queen pheromone in regulating insect sociality. Current Biology, 25: 1638-1640. doi: dx.doi. org/10.1016/j.cub.2015.04.040

Oi, C.A., Van Zweden, J.S., Oliveira, R.C., Van Oystaeyen, A., Nascimento, F.S., \& Wenseleers, T. (2015b). The origin and evolution of social insect queen pheromones: novel hypotheses and outstanding problems. BioEssays, 37: 808821. doi: 10.1002/bies.201400180

Olaniran, A.O., Sudhakar, A.V.S., Drijfhout, F.P., Dublon,
I.A.N., Hall, D.R., Hamilton, J.G.C. \& Kirk, W.D.J. (2013). A male-predominant cuticular hydrocarbon, 7-methyltricosane, is used as a contact pheromone in the western flower thrips Frankliniella occidentalis. Journal Chemical Ecology, 39: 559-568. doi:10.1007/s10886-013-0272-5

Oliveira, O.A.L., Noll, F.B., Mateus, S. \& Gomes, B. (2007). Castes and Asynchronous Colony Cycle in Polybia bistriata (Fabricius) (Hymenoptera: Vespidae). Neotropical Entomology, 36: 817-827.

Oppelt, A. \& Heinze, J. (2009). Mating is associated with immediate changes of the hydrocarbon profile of Leptothorax gredleri ant queens. Journal of Insect Physiology, 55: 624628.

Provost, E., Blight, O., Tirard, A. \& Renucci, M. (2008). Hydrocarbons and insects' social physiology. InR.P. Maes (Ed.), Insect Physiology: new research (19-72). Nova Science Publishers.

Richard, F.J. \& Hunt, J.H. (2013). Intracolony chemical communication in social insects. Insectes Sociaux, 60: 275-291.

Sledge, M.F., Boscaro, F. \& Turillazzi, S. (2001). Cuticular hydrocarbons and reproductive status in the social wasp Polistes dominulus. Behavioral Ecology and Sociobiology, 49: 401-409.

Sledge, M.F., Trinca, I., Massolo, A., Boscaro, F. \& Turillazzi, S. (2004). Variation in cuticular hydrocarbon signatures, hormonal correlates and establishment of reproductive dominance in a polistine wasp. Journal of Insect Physiology, 50: $73-83$

Soares, E.R.P., Torres, V.O., Antonialli-Junior,W.F. (2014) Reproductive status of females in the eusocial wasp Polistes ferreri Saussure (Hymenoptera: Vespidae). Neotropical Entomology, 43: 500-508. doi:10.1007/s13744-014-0242-9

Strassmann, J.E. (1991). Costs and benefits of colony aggregation in the social wasp, Polistes annularis. Behavioral Ecology, 2: 204-209.

Tannure, I.C. \& Nascimento, F.S. (1999). Influência do conflito de dominância entre fundadoras em colônias de vespas sociais pertencentes ao gênero Polistes (Hymenoptera: Vespidae). Revista Brasileira de Zoologia, 1: 31-40.

Tannure-Nascimento, I.C., Nascimento, F.S.,Turatti, I.C., Lopes, N.P., Trigo, J.R. \& Zucchi, R. (2007). Colony membership is reflected by variations in cuticular hydrocarbon profile in a Neotropical paper wasp, Polistes satan (Hymenoptera, Vespidae). Genetics and Molecular Research, 6: 390-396.

Torres, V.O., Sguarizi-Antonio, D., Lima, S.M., Andrade, L.H.C. \& Antonialli-Junior, W.F. (2014). Reproductive status of the social wasp Polistes versicolor (Hymenoptera: Vespidae) Sociobiology, 61: 218-224. 
Van Oystaeyen, A., Oliveira, R.C., Holman, L., Van Zweden, Will, S., Delabie, J.H.C., Heinze, J., Ruther, J. \& Oettler, J.S., Romero, C., Oi, C.A., d'Ettorre, P., Khalesi, M., Billen, J., J. (2012). Cuticular lipid profiles of fertile and non-fertile Wäckers, F., Millar, J.G. \& Wenseleers, T. (2014). Conserved Cardiocondyla ant queens. Journal of Insect Physiology, 58: class of queen pheromones stops social insect workers from reproducing. Science, 343(6168), 287-290. doi: 10.1126/ science. 1244899

1245-1249. doi: 10.1016/j.jinsphys.2012.06.009.

Wilson, E. O. (1971). The insect societies. Belknap, Cambridge, 548 p.

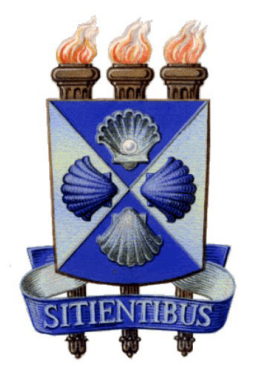

